\title{
Temporal gamma-diversity meets spatial alpha-diversity in dynamically varying ecosystems
}

\author{
David M. Mushet $^{1}$ (D) Matthew J. Solensky ${ }^{1}$ (D) Shay F. Erickson $^{1}$ (D)
}

Received: 21 August 2018 / Revised: 20 March 2019 / Accepted: 29 March 2019 / Published online: 4 April 2019 (c) The Author(s) 2019

\begin{abstract}
Community measures collected at a single instance or over a short temporal period rarely provide a complete accounting of biological diversity. The gap between such "snapshot" measures of diversity and actual diversity can be especially large in systems that undergo great temporal variation in environmental conditions. To adequately quantify diversity in these temporally varying ecosystems, individual measures of diversity collected throughout the range of environmental variation, i.e., temporal alpha-diversity measures, must be combined to obtain temporal gamma-diversity. Such a time-integrated gamma-diversity measure will be a much closer approximation of a site's true alpha-diversity and provide a measure better comparable to spatial alpha-diversity measures of sites with lower temporal variation for which a single or a few "snapshot" measures may suffice. We used aquatic-macroinvertebrate community-composition data collected over a 24-year period from a complex of 16 prairie-pothole wetlands to explore the rate that taxa accumulate over time at sites with differing degrees of temporal variation. Our results show that the rate of taxa accumulation over time, i.e., the slope of the species-time relationship, is steeper for wetlands with ponds that frequently dry compared to those with more-permanent ponds. Additionally, we found that a logarithmic function better fit species accumulation data for seasonally ponded wetlands whereas a power function better fit accumulations for permanently and semi-permanently ponded wetlands. Thus, interpretations of ecological diversity measures, and conservation decisions that rely on these interpretations, can be biased if temporal variations in community composition are not adequately represented.
\end{abstract}

Keywords Biodiversity $\cdot$ Ecological variability $\cdot$ Measuring diversity $\cdot$ Prairie-pothole wetlands $\cdot$ Species-time relationship $\cdot$ Species-time slope $\cdot$ Temporal diversity

Communicated by P. Ponel.

Electronic supplementary material The online version of this article (https://doi.org/10.1007/s1053 1-019-01756-1) contains supplementary material, which is available to authorized users.

David M. Mushet

dmushet@usgs.gov

1 Northern Prairie Wildlife Research Center, U.S. Geological Survey, 8711 37th Street SE, Jamestown, ND 58401, USA 


\section{Introduction}

The diversity of ecological communities has long been studied (Magurran and McGill 2011) and provided the core around which much of Darwin's thinking about the process of natural selection was formed (Darwin 1859). In more contemporary times, maintenance of biodiversity has been a major force influencing many conservation decisions related to the acquisition, size, and distribution of nature preserves; habitat management; environmental toxification; and climate change (Ehrlich and Pringle 2008). Whittaker (1960) was the first to distinguish among three types of biological diversity, alpha, beta, and gamma. Whittaker used these diversity types to describe diversity of specific sites (alpha diversity), compositional differences among sites (beta diversity), and total diversity of multiple sites or a landscape (gamma diversity). These same spatial concepts have similarly been applied to temporal changes that occur at a site, with alpha diversity being the diversity of a site at a particular point in time, beta diversity referring to changes in diversity of a site over time, and gamma diversity relating to the total diversity of a site over time (Magurran 2011). However, with few exceptions (e.g., Hadly and Maurer 2001; Jacquemyn et al. 2001; Zajac et al. 2013), diversity is either measured on a spatial scale within a landscape or, much more rarely, on a temporal scale at a specific site through time; and the two concepts are not combined.

Species richness, the number of species in a defined area or community, is a conceptually simple and iconic measure of diversity often synonymous with alpha diversity. However, species richness can be surprisingly difficult to measure despite its apparent simplicity (Magurran and McGill 2011). One of the aspects that makes the measurement of species richness troublesome is that increased sampling effort, either in space or time, invariably leads to an increase in species-richness estimates (Preston 1960; Gotelli and Colwell 2001). Of the two "space or time," accounting for the accumulation of species through time usually receives the least attention, likely due to the expense and time-commitment associated with long-term data collection efforts needed to determine species-time relationships (STRs). In a review of all papers published in Biodiversity and Conservation in the a 10-year period (2008-2017), we found that of 854 papers that included comparisons of species diversity among sites or points-in-time (Online Resource 1), only 18 accounted for the accumulation of species over time, i.e., quantified the STR. However, this lack of consideration of the STR does not negate the importance of including this aspect of species richness in the evaluation, comparison, or conservation of ecological communities, especially for communities that naturally have a high temporal species-accumulation rate, i.e., communities with high temporal beta diversity.

Using long-term, plant-community data from a Kansas prairie, Adler and Lauenroth (2003) showed that the cumulative increase in species richness over time, i.e., the STR, takes the same power-law form as the relationship between species richness and area, i.e., the species-area relationship (SAR). However, while the slope of the SAR has been shown to be similar for a broad range of taxa in many ecosystems (White et al. 2006), it is not known if the slope of the STR is similarly robust. In fact, Adler and Lauenroth (2003) postulated that the STR slope would be steeper in ecosystems subjected to increasing levels of environmental variability due to species being favored differently under the varied environmental conditions unique to differing points in time.

Wetlands of the Prairie Pothole Region of North America squarely fall into the category of ecosystems influenced by great environmental variability, variability that is driven largely by the region's dynamic climate. In this environmentally dynamic region, wetlands 
are one of the most dynamic of all ecosystem types, varying from a complete absence of ponded water during drought conditions, to flooded during periods of deluge (Winter and Rosenberry 1998). Additionally, variation among wetlands in terms of their ability to retain ponded water during a given year can add to the overall environmental variability, with the ponds of many wetlands drying after a few weeks or few months following initial ponding, while those of other wetlands retain ponded water throughout the year (Niemuth et al. 2010). We used aquatic-macroinvertebrate community data collected over a 24-year period from 16 prairie-pothole wetlands to quantify the rate by which taxa accumulate over time (the STR) in these environmentally dynamic ecosystems and to explore how ecological interpretations can be biased if temporal variations are not adequately represented in biological diversity measures. We also calculated the slope of the STR for aquatic-macroinvertebrate communities of these wetlands for comparison with STR slopes representative of other taxa and ecosystems.

\section{Methods}

\section{Study area}

The 92-ha Cottonwood Lake Study Area (CLSA) is located in south-central North Dakota along the eastern edge of a glacial stagnation moraine known as the Missouri Coteau (Fig. 1). The CLSA has been the focus of biological, hydrological, and geochemical research (e.g., see Winter 2003) since the U.S. Fish and Wildlife Service purchased the site from private landowners in 1963. In 1992, the last full year of an especially severe drought that persisted from 1988 to July of 1993, quantitative investigations of the aquaticinvertebrate communities inhabiting wetlands within the study area were initiated. The 16 wetlands occurring at the study area consist of seven semi-permanently ponded wetlands (identified as wetlands P1-4, and P6-8) that only lack ponded water during periods of drought, a single permanently ponded wetland (identified as wetland P11), and eight seasonally ponded wetlands (identified as wetlands T2-9) with ponds that dry annually in all but the wettest years. While wetland P11 is classified as a permanently ponded wetland, even this wetland can lack ponded water during years of extreme drought (e.g., 1992). Wetlands P5, P9, and P10 were included in the original numbering system of wetlands in the vicinity of Cottonwood Lake; however, they are located outside the boundaries of the CLSA proper and were not included in long-term, aquatic-invertebrate, sampling efforts. Additionally, we did not consider the area identified as wetland T1 to be a separate wetland because its surface-water pond was joined with the pond of wetland P1 in all years of our 24-year study period, except 1992.

The plant communities of prairie-pothole wetlands tend to occur as bands within the wetland basin. These "vegetation zones" are associated with differences in water depth and permanence along a gradient from the upland surrounding a wetland to the deepest point in a wetland's basin (Stewart and Kantrud 1972). Semi-permanently ponded wetlands usually have a deep-marsh zone in their center that can either be populated by deep-marsh-emergent or submerged vegetation (Stewart and Kantrud 1971). When populated by submerged vegetation or when lacking vegetation, this central zone is often referred to as an "openwater" zone. The deep-marsh zone and open-water zones are often surrounded by a band of shallow-marsh vegetation (i.e., the shallow-marsh zone). Wet-meadow vegetation (i.e., the wet-meadow zone) dominates the outermost plant community of most prairie-pothole 


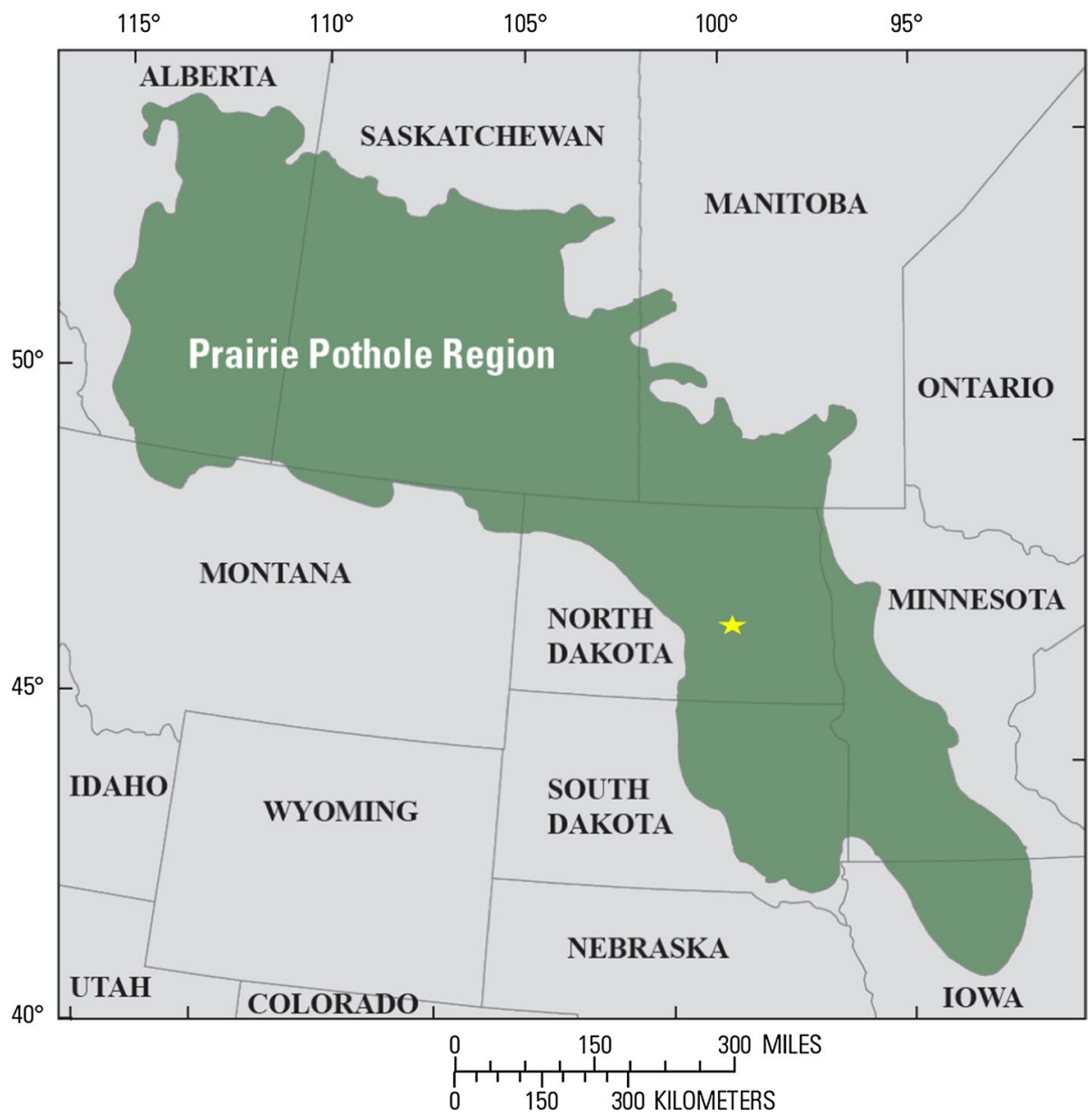

Fig. 1 Location of the Cottonwood Lake Study Area (yellow star) in the Prairie Pothole Region of North America

wetlands. Due to their shallower, and less-permanent ponds, seasonally ponded wetlands typically lack deep-marsh and open-water zones, with plant communities forming into only a shallow-marsh zone that is immediately surrounded by a wet-meadow zone on the upland edge of the wetland (Stewart and Kantrud 1971). Permanently ponded wetlands are characterized by a large and persistent open-water zone in the central portion of the wetland (Stewart and Kantrud 1971).

\section{Aquatic-macroinvertebrate sampling}

We have sampled the aquatic-macroinvertebrate communities of sixteen CLSA wetlands annually since 1992 using vertically oriented, downward-facing, aquatic-invertebrate, funnel traps (Swanson 1978). Within a year, sampling is conducted once each month beginning soon after ice-out in April and ending in September before the pond refreezes for the 
winter. During a monthly sampling event, a total of nine traps are deployed at randomly located points within each of three vegetation zones (shallow-marsh, deep-marsh and openwater) as bisected by three systematically located transects that radiate from the wetland center (one trap per zone per transect). The wet-meadow zone was not sampled because ponded water rarely inundates this outer-most zone to a depth sufficient for the placement of funnel traps. Thus, within each wetland, three samples were collected from each of three vegetation zones each of 6 months, for a maximum of 54 samples per wetland. However, not all wetlands contained all three zones (e.g., seasonal wetlands typically lacked both a deep-marsh and an open-water zone), and samples were not collected in a vegetation zone if water depth in that zone was $<25 \mathrm{~cm}$, resulting in many instances for which the total number of samples collected from a wetland in a year was $<$ the 54 -sample maximum.

Following retrieval of a funnel trap from a wetland, the trap contents were sieved through a $0.5-\mathrm{mm}$ stainless-steel screen. All invertebrates and other materials not passing through the $0.5-\mathrm{mm}$ screen were rinsed into a $475-\mathrm{ml}$, plastic, sample container and ethyl alcohol $(80 \%)$ was added to the sample as a preservative. Following preservation, samples were taken to a USGS laboratory in Jamestown, ND for processing. Sample processing consisted of transferring a collected and preserved sample into a stainless-steel beaker with a 0.5 -mm-mesh screened side. The sample was then rinsed with water to remove the alcohol and any remaining invertebrates or debris that would pass through the $0.5-\mathrm{mm}$ screen. Once rinsed, the sample was transferred to a Pyrex glass tray for sorting of invertebrates from debris. Sorting of samples was conducted over a light box and consisted of meticulously transferring all macroinvertebrates (i.e., invertebrates too large to pass through the 0.5 -mm screens used in collection and rinsing of samples) to a Petri dish. All macroinvertebrates were identified to the lowest taxonomic resolution feasible (usually genus, but sometimes family) and enumerated by taxa. Taxa determinations were facilitated through the use of identification keys provided in Thorp and Covich (1991) and Smith (2001). All data were double entered into Excel spreadsheets, checked for errors, corrected as needed, and archived as an openly available.csv file in ScienceBase at: https://www.sciencebas e.gov/catalog/item/599d9555e4b012c075b964a6.

\section{Data analyses}

To explore how total aquatic-macroinvertebrate taxon-richness estimates across all sampled wetlands varied among years, we calculated a Jaccard incidence-based similarity index $\left(C_{J}\right.$; Magurran 1988) for each year-by-year pairwise comparison. We used the formula $C_{J}=S_{a b} /\left(S_{a}+S_{b}-S_{a b}\right)$, where $S_{a}$ is the number of species in year $a, S_{b}$ is the number of species in year $b$, and $S_{a b}$ is the number of species shared in both years $a$ and $b$. The number of species in a year was quantified from the CLSA trapping data as the total number of unique taxa summed across all sampling events in a given year. The Jaccard Index can range between zero and one. If the communities in years $a$ and $b$ did not share any taxa, $S_{a b}$ would be zero and thus $C_{J}$ would also $=0$. By contrast, if all taxa were shared between years, $C_{J}$ would $=1$. Most pairwise comparisons fall between these two extremes.

We next followed procedures similar to Adler and Lauenroth (2003) to determine the STR for each of the 16 CLSA wetlands. We generated STRs for the individual wetlands by calculating the average number of unique taxa occurring in periods of consecutive years, $S_{T}$, ranging from 1 to 24 years. Thus, over the 24-year record of our aquatic-macroinvertebrate sampling, we had 24 replicates for the period $T=1,23$ replicates for the period $T=2,22$ replicates for the period $T=3$, etc., concluding with a single replicate of 
$T=24$. We determined STR using the power function $S=c T^{w}$, where c is an approximation of observed species richness and $w$ is the linearized STR slope on log-transformed axes. Since STRs fit using power-law and logarithmic functions provide different information on how community composition changes over time (White et al. 2006), we also fit the STR using the logarithmic function $S=c+w \log T$. We plotted resultant taxon-richness means in both $\log -\log \left(\ln S_{T}\right.$ on $\left.\ln T\right)$ and semi-log $\left(S_{T}\right.$ on $\left.\ln T\right)$ space for power and logarithmic functions, respectively, and used ordinary least-squares regressions to determine linear relationships. We used a one-tailed $t$ test assuming unequal variances to compare the slopes of the STRs (both power and logarithmic) for seasonally ponded wetlands at the CLSA (CLSA wetlands T3-9) to the STR slopes of the study area's semi-permanently ponded wetlands (CLSA wetlands P1-4, P6-8). Note that we did not include wetland T2 with the seasonally ponded wetlands in our t-test comparisons as wetland $\mathrm{T} 2$ has a strong groundwater influence, rarely dries completely, and often has a surface-water connection to wetland P8 (Leibowitz et al. 2016). Also, we only had a single replicate of a permanently ponded wetland (CLSA wetland P11), so this wetland was also excluded from our t-test comparisons, but both wetlands P11 and T2 are included in our STR plots and function fits.

\section{Results}

We identified a total of 159, unique, aquatic-invertebrate taxa occurring in wetlands of the CLSA over our 24-year (1992-2015) study. Aquatic-macroinvertebrate taxon richness in individual wetlands varied greatly across years, ranging from 0 when wetlands failed to pond water during drought years to 64 in semi-permanently ponded wetland P8 in 2007. Taxon richness for seasonally ponded wetlands T2-9 ranged from 0 to 56 with a mean across wetlands and years of 28.8. Taxon richness for the semi-permanently ponded wetlands (wetlands P1-4 and P6-8) was typically greater, ranging from 0 to 64 with a mean across wetlands and years of 36.6. The taxa richness for the single, permanently ponded wetland (wetland P11) ranged from 0 when dry in 1992 to 49 in 1995. It should be noted that the aquatic-invertebrate funnel traps used to sample CLSA wetlands require the active movement of individuals into the trap. Thus, our diversity estimates are biased towards more-active species. However, the vertical and downward-facing orientation of the deployed traps allowed the traps to sample all invertebrates that moved through the water column, including benthic species as they moved to the pond surface during emergence events.

The Jaccard similarity index for all wetlands combined (Table 1) ranged from a low of 0.34 (1992 vs. 2012) to a high of 0.84 (1997 vs. 1998). As expected, $C_{J}$ was consistently higher (i.e., more similar) for aquatic-macroinvertebrate communities in consecutive years than for communities separated by multiple years. However, the range (0.34-0.84) was especially large, given that the taxa richness estimates were for the entire set of wetlands at the CLSA, and not individual wetland basins.

In agreement with Adler and Lauenroth (2003), we found that the fits of the untransformed STRs (Fig. 2) were highly linear when plotted in $\log -\log$ space (mean $\mathrm{R}^{2}=0.985$; Fig. 3 ). The slopes of the linearized species-time power function over the 24-year period ranged from 0.227 for wetland P8 to 0.383 for wetland T5 (Table 2). As hypothesized, the slope of the linearized power function was significantly greater $(\mathrm{t}-\mathrm{stat}=2.072 ; \mathrm{df}=8 ; \mathrm{P}=0.0360$ ) for seasonally ponded wetlands (mean slope $=0.351$, variance $=0.0003$ ) versus semi-permanently ponded wetlands (mean slope $=0.309$, variance $=0.0026$ ). While overall, power functions fit 


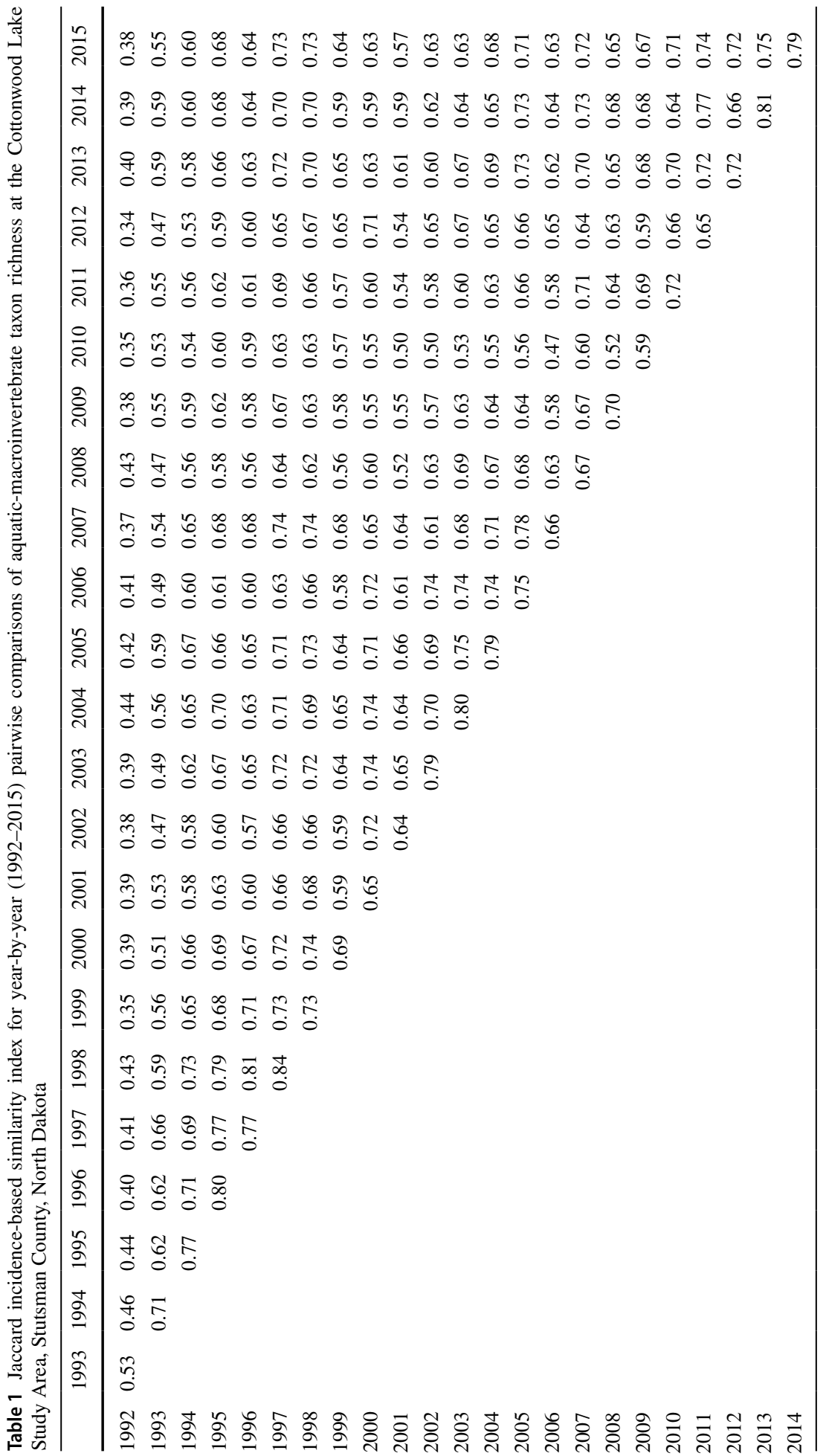


better (mean $\mathrm{R}^{2}=0.985$ ) than logarithmic functions (mean $\mathrm{R}^{2}=0.978$; Fig. 4), for individual wetlands this finding was limited primarily to the semi-permanently and permanently ponded wetlands (Fig. 5). Logarithmic functions provided better fits for all but one (wetland T9) seasonally ponded wetland. Additionally, species-accumulation data for semi-permanently ponded wetlands P3 and P8 were also better fit by logarithmic functions (Table 2).

\section{Discussion}

While it is a widely known that species accumulate over time, it is surprising how rarely

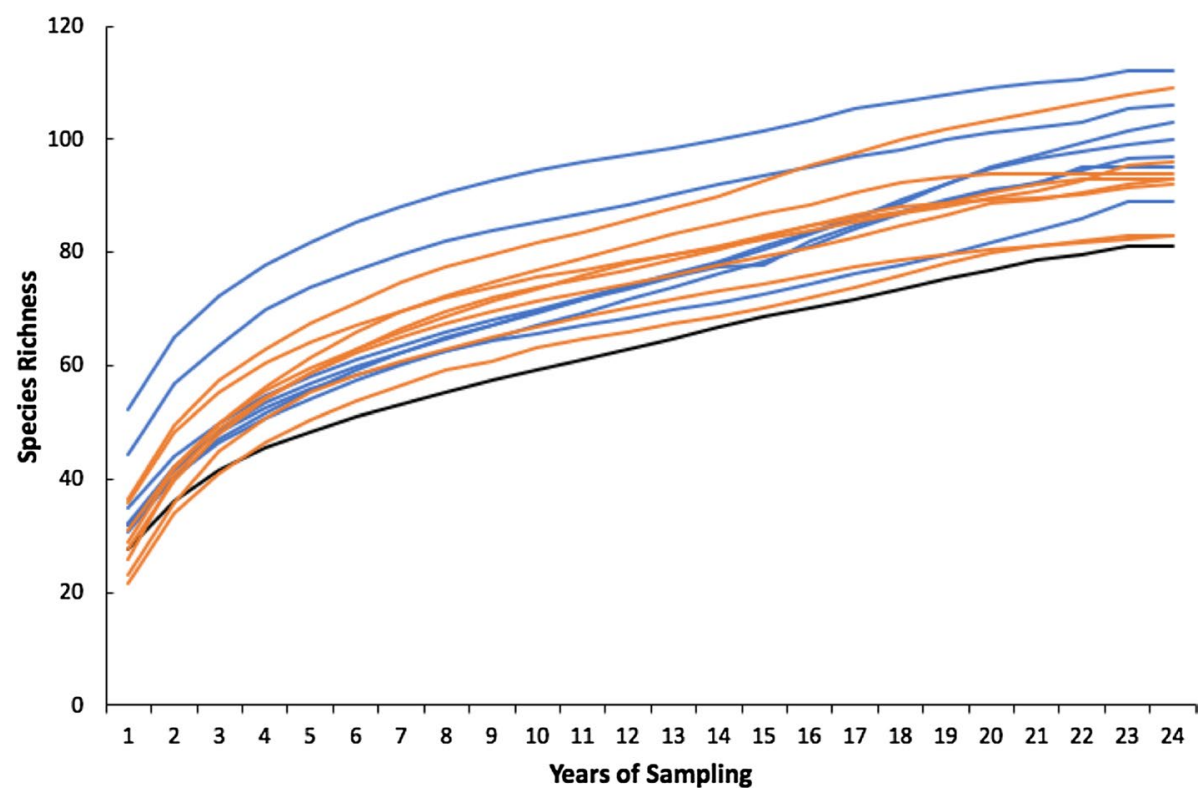

Fig. 2 Regression lines for aquatic-macroinvertebrate taxa-accumulation rates (i.e., species-time relationships) for 16 wetlands at the Cottonwood Lake Study Area, Stutsman County, North Dakota, 1992-2015, plotted in untransformed species-time space. Orange lines seasonally ponded wetlands, blue lines semipermanently ponded wetlands, black line the single permanently ponded wetland

the important influences of these accumulations are incorporated into species richness estimates. This is likely a result of time commitments and costs often associated with long-term, data-collection efforts. However, it is equally surprising how rarely lack of including this important driver of species richness and its influence on richness estimate is acknowledged. Of the 854 Biodiversity and Conservation papers we reviewed (Online Resource 1), only 141 acknowledged potential influences of STRs on diversity measures. Of these 141, over half (73) focused only on the need to sample multiple times across a season to capture seasonal variation in species occurrence but did not discuss the potential influence of species accumulations across greater temporal periods, e.g., years to decades. Our results showing significant differences in species accumulation rates of aquatic-invertebrate communities of seasonally, semi-permanently, and permanently ponded wetlands in the Prairie Pothole Region should spawn concerns related 


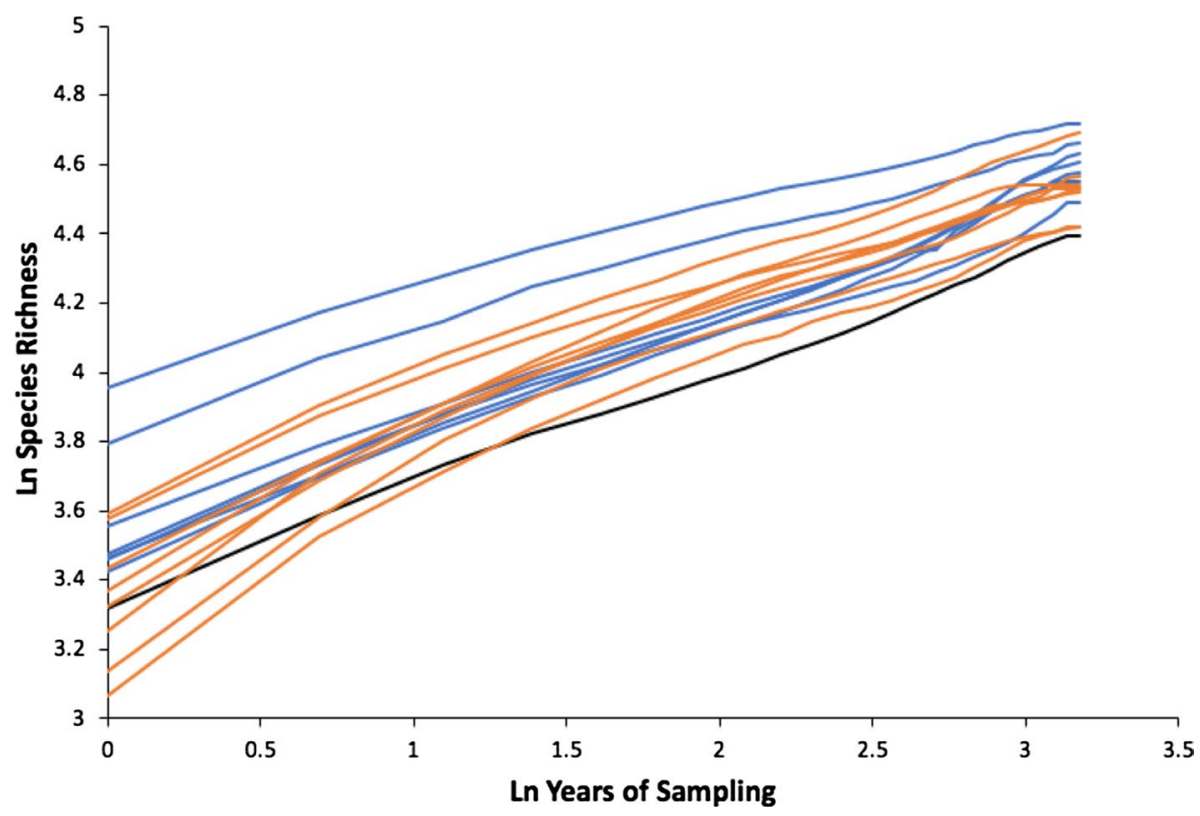

Fig. 3 Regression lines for aquatic-macroinvertebrate taxa-accumulation rates (i.e., species-time relationships) for 16 wetlands at the Cottonwood Lake Study Area, Stutsman County, North Dakota, 1992-2015, plotted in $\log -\log$ space (i.e., $\ln S_{T}$ on $\left.\ln \mathrm{T}\right)$. Orange lines seasonally ponded wetlands, blue lines semipermanently ponded wetlands, black line the single permanently ponded wetland

to other ecosystems for which the influence of species accumulations over time have not been adequately considered. Since determining STRs often requires long-term data resources (Tomasovych and Kidwell 2010), the importance of maintaining long-term data-collection efforts and starting new efforts in diverse ecosystems throughout the world cannot be overstated (e.g., Vihervaara et al. 2013).

The Jaccard indices we calculated for aquatic macroinvertebrate communities of CLSA wetlands show that, while communities between any 2 years are about $70-80 \%$ similar, that similarity quickly declines as years of separation increase. This is a good indicator of the importance of sampling across multiple years to adequately represent the true diversity of these wetlands and account for changes in taxa composition in response to natural environmental cycles as opposed to true losses of taxa from a site. Also, we found that the rate of species accumulation at CLSA was greatest in the seasonally ponded wetlands (i.e., the most temporarily varying wetlands). This is significant as these wetlands are often the most vulnerable to loss due to anthropogenic disturbance (Calhoun et al. 2017), and their underrepresented diversity might contribute to undervaluing of their ecological importance. Likewise, the slope of the STR was lowest in the single permanently ponded wetland (Figs. 2, 3, 4). Thus, our results support the hypothesis of Adler and Lauenroth (2003) that, as environmental variability increases, species accumulate at a greater rate over time. Additionally, our sampling effort was limited to the aquatic macro-invertebrates that occurred in the ponded water of a wetland. If we increased our effort to include the terrestrial invertebrates that populate wetlands basins when a wetland's pond dries, we would expect the species accumulation 
Table 2 Fit of linearized, species-time, power and logarithmic functions for seasonally ponded wetlands T2-9, semi-permanently ponded wetlands P1-4 and P6-8, and permanently ponded wetland P11 at the Cottonwood Lake Study Area (CLSA), Stutsman County, North Dakota, 1992-2015

\begin{tabular}{lllll}
\hline $\begin{array}{l}\text { CLSA wetland } \\
\text { IDs }\end{array}$ & $\begin{array}{l}\text { Power function } \\
\text { slope }\end{array}$ & $\begin{array}{l}\text { Logarithmic function } \\
\text { slope }\end{array}$ & Power function $R^{2}$ & $\begin{array}{l}\text { Logarithmic } \\
\text { function } R^{2}\end{array}$ \\
\hline T2 & 0.2793 & 18.199 & 0.9847 & $\mathbf{0 . 9 9 0 5}$ \\
T3 & 0.3318 & 20.535 & 0.9911 & $\mathbf{0 . 9 9 4 4}$ \\
T4 & 0.3576 & 18.855 & 0.9553 & $\mathbf{0 . 9 9 8 8}$ \\
T5 & 0.3828 & 19.495 & 0.9762 & $\mathbf{0 . 9 9 0 9}$ \\
T6 & 0.3536 & 21.870 & 0.9760 & $\mathbf{0 . 9 9 6 0}$ \\
T7 & 0.3535 & 20.573 & 0.9694 & $\mathbf{0 . 9 9 3 3}$ \\
T8 & 0.3536 & 21.036 & 0.9782 & $\mathbf{0 . 9 9 7 6}$ \\
T9 & 0.3255 & 23.224 & $\mathbf{0 . 9 9 3 9}$ & 0.9811 \\
P1 & 0.3560 & 21.808 & $\mathbf{0 . 9 9 3 1}$ & 0.9464 \\
P2 & 0.3519 & 22.302 & $\mathbf{0 . 9 9 1 5}$ & 0.9449 \\
P3 & 0.2550 & 19.182 & 0.9907 & $\mathbf{0 . 9 9 3 8}$ \\
P4 & 0.3448 & 21.291 & $\mathbf{0 . 9 9 7 2}$ & 0.9636 \\
P6 & 0.3316 & 21.756 & $\mathbf{0 . 9 8 5 1}$ & 0.9289 \\
P7 & 0.2933 & 17.295 & $\mathbf{0 . 9 8 8 7}$ & 0.9629 \\
P8 & 0.2269 & 18.922 & 0.9911 & $\mathbf{0 . 9 9 7 7}$ \\
P11 & 0.3319 & 17.612 & $\mathbf{0 . 9 9 6 6}$ & 0.9671 \\
Mean & 0.3276 & 20.376 & $\mathbf{0 . 9 8 4 9}$ & 0.9780 \\
\hline
\end{tabular}

Bold text indicates the higher of the two $\mathrm{R}^{2}$ values for power-function versus logarithmic-function comparisons

rate to be even greater in wetlands that frequently dry, i.e. the seasonally ponded wetlands. Thus, while seasonally ponded wetlands are generally believed to support lowerdiversity invertebrate communities than permanently and semi-permanently ponded wetlands (Euliss et al. 1999), a different perspective will likely emerge once temporal accumulations of species are adequately considered.

The average power-function slopes for aquatic-macroinvertebrate communities of the CLSA (0.328) fit well within the range of average species accumulation rates from other taxa and study areas (range $=0.23-0.39$ ) as summarized by White et al. (2006). White et al. (2006) found that the mean power-function slope for vertebrates, i.e., fish, birds, and mammals, were very similar, ranging from 0.23 to 0.26 . For land-plants and algae, average slopes were 0.39 and 0.24 , respectively. For the invertebrate taxa they considered (grasshoppers, intertidal invertebrates, corals, and zooplankton), average power-function slopes ranged from 0.23 to 0.37 , i.e., almost identical to the $0.22-0.38$ range we observed for aquatic-macroinvertebrate communities of the individual freshwater wetlands of the CLSA.

While we found that, in general, power functions provided the best fit for semi-permanently and permanently ponded wetlands, and logarithmic function better fit species accumulations in seasonally ponded wetlands (Fig. 5), curve fitting does not identify the underlying processes that result in these differing STRs (McGill 2003). Thus, a deeper understanding of the system is needed to infer processes driving differences in the STRs among communities and ecological significance. For the CLSA, long-term research into the ecological processes driving wetland ecosystems sheds some light on the differences 


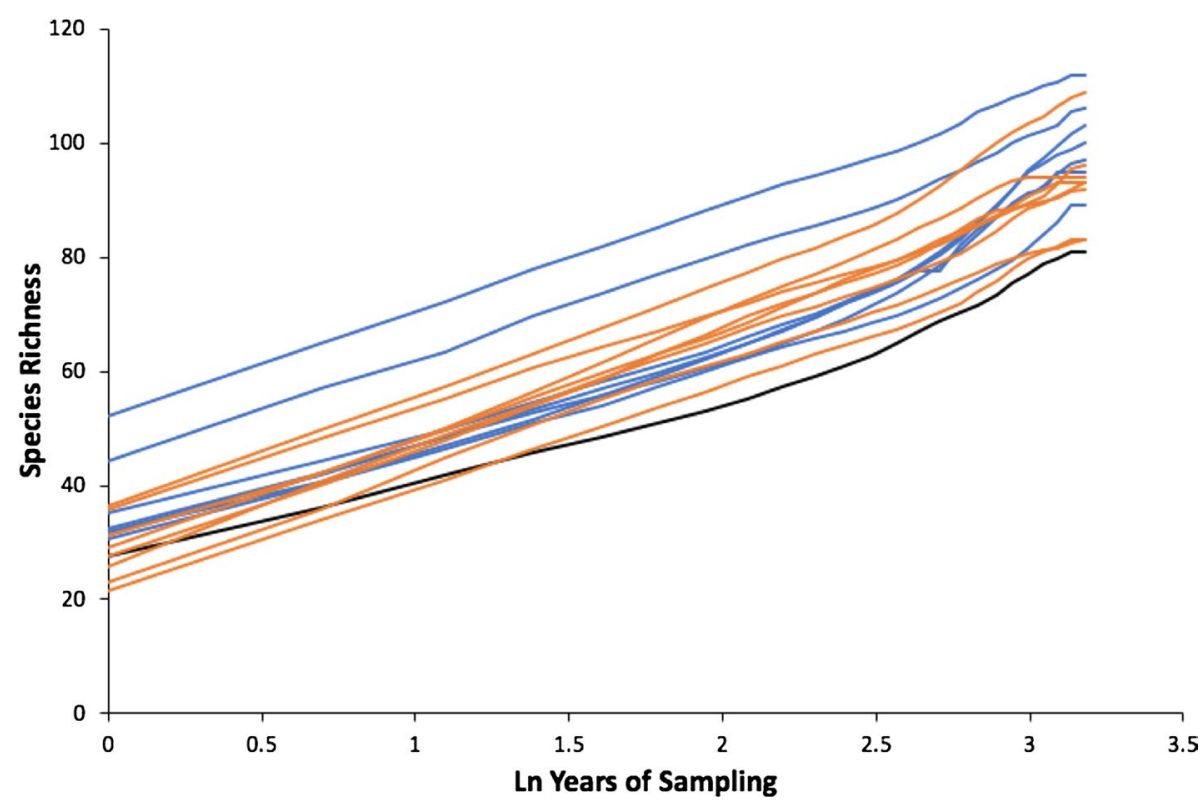

Fig. 4 Regression lines for aquatic-macroinvertebrate taxa-accumulation rates (i.e., species-time relationships) for 16 wetlands at the Cottonwood Lake Study Area, Stutsman County, North Dakota, 1992-2015, plotted in semi-log space (i.e., $S_{T}$ on $\ln \mathrm{T}$ ). Orange lines seasonally ponded wetlands, blue lines semi-permanently ponded wetlands, black line the single permanently ponded wetland

we observed. For seasonal wetlands, a logarithmic function better fits the rapid accumulations of species during the first few years of sampling, a rate that then changes to more closely match that of the semi-permanently and permanently ponded wetlands that do not experience seasonal drying.

We only found three exceptions to the pattern that power functions better fit aquaticmacroinvertebrate species accumulations in semi-permanently and permanently ponded wetlands while logarithmic functions better fit accumulations in seasonally ponded wetlands. Only two of the semi-permanently ponded wetlands (wetlands P3 and P8) were best fit by a logarithmic versus a power function. Interestingly, these were the only two semipermanently ponded wetlands studied with an overland spill-point that limits maximum ponded-water depth in the wetland. All other semi-permanent wetlands in the study area had closed basins and did not lose water as spillage. The influence of a spill point in terms of limiting maximum water depth to the basin's spill-point elevation resulted in ponded waters fluctuating very differently in these two wetlands relative to the other semi-permanently ponded wetlands at the site (LaBaugh et al. 2016). By contrast, wetland T9 was the only seasonally ponded wetland for which a power function provided the best fit. However, during the period of our study, this wetland maintained a ponded-water depth much greater than any of the other seasonally ponded wetlands and did not regularly dry (LaBaugh et al. 2016). Therefore, during most of the 24-year period of our study, this wetland functioned more similarly to a semi-permanently rather than a seasonally ponded wetland. Thus, by identifying cases that do not fit expected logarithmic or power functions, additional information on ecological and community processes is revealed.

Pärtel et al. (2011) defined "dark diversity" as the species that are missing from a site but are present in similar habitats on the larger landscape. We propose that the absence of 

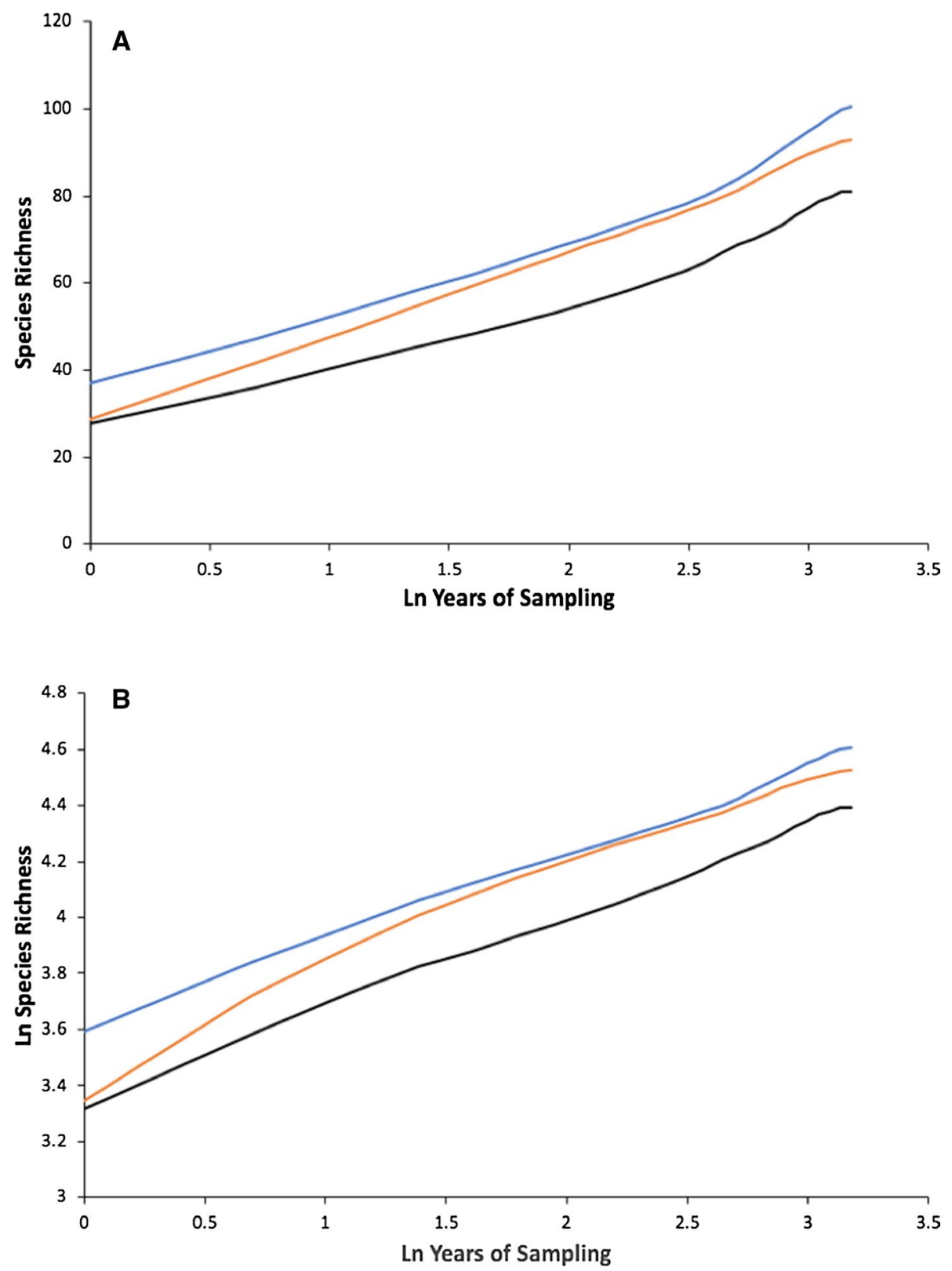

Fig. 5 Average taxa-accumulation rates (i.e., species-time relationships) for 16 wetlands at the Cottonwood Lake Study Area, Stutsman County, North Dakota, 1992-2015, plotted in a semi-log space and b log-log space. Orange line average of seasonally ponded wetlands T3-9, blue lines average of semi-permanently ponded wetlands P1-4 and P6-8, black line value for the single permanently ponded wetland P11

specific taxa during certain temporal periods in dynamic systems is related to the "dark diversity" concept discussed by (Pärtel et al. 2011). In a temporal sense, dark diversity could be viewed as being the species that are absent from a site at a particular point in 
time, but likely to return reappear at the site as environmental conditions fluctuate through time. Thus, just as relating observed diversity and dark diversity facilitate comparisons of ecosystems and communities across differing regions (Pärtel et al. 2011), comparisons of observed diversity and temporal dark diversity could facilitate comparisons among ecosystems with differing species-accumulation rates. As an example, a seasonally ponded wetland in the Prairie Pothole Region would likely have a large portion of its diversity occurring in the temporal "dark-diversity" pool at any single point in time. Thus, sampling of that wetland would necessarily need to occur over a longer period to obtain a diversity measure comparable to that of a system with a higher proportion of its species pool present and available for observation, i.e., a wetland with a smaller dark-diversity pool. The observed-diversity/temporal-dark-diversity ratio of sites could be used to standardize comparisons among sites with differing environmental variation and is closely related to a site's temporal beta diversity. Identification of a system's temporal dark-diversity also provides an indication of the magnitude of diversity loss that could occur if natural levels of environmental variability were reduced for a site.

Given the importance of species accumulations over time in determining the actual diversity of a site and the fact that more dynamic systems accumulate species at a faster rate than those with lower environmental variation, determination of STRs is needed to provide unbiased comparisons of diversity among systems. This need for a long-term view of biological diversity can be viewed as analogous to how climate for an area is determined from long-term weather data. It is not possible to determine the climate of an area with just a single snapshot of temperature, precipitation, etc. However, in areas with little variation in these factors, a few years of data may suffice in describing that region's climate. However, in most areas of the world, multiple decades (typically 30 years) of data are needed to accurately define a climate (Arguez and Vose 2011). The biodiversity of an area can be viewed in a similar way. In sites with low temporal variability in communities, i.e., sites with low temporal beta diversity, only a few measures may be needed to get an accurate quantification of temporal gamma diversity of that site. However, in more temporally diverse systems with their resultant high temporal beta diversity, long-term data that allow for the accounting of species accumulations over time are needed to adequately represent temporal gamma diversity. Since in dynamic systems temporal gamma diversity is the best measure of a site's sites true diversity, this measure should be used to represent that site's spatial alpha diversity. Other alpha diversity measures will fall short in accounting for species that form a part of a sites biodiversity but, due to environmental fluctuations, may only exist in a site's temporal dark-diversity pool during specific periods of time.

Acknowledgements Our work would not have been possible except for the efforts of George A. Swanson (deceased) who established the Cottonwood Lake Study Area in 1967 and Ned H. Euliss, Jr. who initiated the long-term, aquatic-macroinvertebrate, monitoring efforts at the site in 1992. We also thank the many technicians, biologists, ecologists, student contractors, and volunteers who have worked over the years to collect and process aquatic-macroinvertebrate samples from the site. All invertebrate count data from the Cottonwood Lake Study Area used in our analyses have been released and are publicly available at: https ://www.sciencebase.gov/catalog/item/599d9555e4b012c075b964a6. Funding for this effort was provided by the Research and Development component of the USGS Land Change Science Program. Any use of trade, firm, or product names is for descriptive purposes only and does not imply endorsement by the U.S. Government.

Open Access This article is distributed under the terms of the Creative Commons Attribution 4.0 International License (http://creativecommons.org/licenses/by/4.0/), which permits unrestricted use, distribution, and reproduction in any medium, provided you give appropriate credit to the original author(s) and the source, provide a link to the Creative Commons license, and indicate if changes were made. 


\section{References}

Adler PB, Lauenroth WK (2003) The power of time: spatiotemporal scaling of species diversity. Ecol Lett 6:749-756

Arguez A, Vose RS (2011) The definition of the standard WMO climate normal: the key to deriving alternative climate normals. Bull Am Meteorol Soc 92:699-704

Calhoun AJK, Mushet DM, Bell KP, Boix D, Fitzsimonse JA, Isselin-Nondedeug F (2017) Temporary wetlands: challenges and solutions to conserving a 'disappearing' ecosystem. Biol Conserv 211b:3-11

Darwin C (1859) On the origin of species by means of natural selection, or the preservation of favored races in the struggle for life. John Murray, London

Ehrlich PR, Pringle RM (2008) Where does biodiversity go from here? A grim business-as-usual forecast and a hopeful portfolio of partial solutions. Proc Natl Acad Sci USA 105(Suppl. 1):11579-11586

Euliss NH Jr, Mushet DM, Wrubleski DA (1999) Chapter 21: wetlands of the Prairie Pothole Region: invertebrate species composition, ecology, and management. In: Batzer DP, Rader RB, Wissinger SA (eds) Invertebrates in freshwater wetlands of North America: ecology and management. Wiley, New York, pp 471-514

Gotelli NJ, Colwell RK (2001) Quantifying biodiversity: procedures and pitfalls in the measurement and comparison of species richness. Ecol Lett 4:379-391

Hadly EA, Maurer BA (2001) Spatial and temporal patterns of species diversity in montane mammal communities of western North America. Evol Ecol Res 3:477-486

Jacquemyn H, Butaye J, Hermy M (2001) Forest plant species richness in small fragmented mixed deciduous forest patches: the role of area, time and dispersal limitation. J Biogeogr 28:801-812

LaBaugh JW, Mushet DM, Rosenberry DO, Euliss NH Jr, Goldhaber MB, Mills CT, Nelson RD (2016) Changes in pond water levels and surface extent due to climate variability alter solute sources to closed-basin prairie-pothole wetland ponds, 1979 to 2012. Wetlands 36(Suppl 2):S343-S355

Leibowitz SG, Mushet DM, Newton WE (2016) Intermittent surface water connectivity: fill and spill vs. fill and merge dynamics. Wetlands 36(Suppl 2):S323-S342

Magurran AE (1988) Ecological diversity and its measurement. Princeton University Press, Princeton

Magurran AE (2011) Measuring biological diversity in time (and space). In: Magurran AE, McGill BJ (eds) Biological diversity: frontiers in measurement and assessment. Oxford University Press, Oxford, pp $85-94$

Magurran AE, McGill BJ (2011) Challenges and opportunities in the measurement and assessment of biological diversity. In: Magurran AE, McGill BJ (eds) Biological diversity: frontiers in measurement and assessment. Oxford University Press, Oxford, pp 1-7

McGill B (2003) Strong and weak tests of macroecological theory. Oikos 102:679-685

Niemuth ND, Wangler B, Reynolds RE (2010) Spatial and temporal variation in wet area of wetlands in the Prairie Pothole Region of North Dakota and South Dakota. Wetlands 30:1053-1064

Pärtel M, Szava-Kovats S, Zobel M (2011) Dark diversity: shedding light on absent species. Trends Ecol Evol 26:124-218

Preston FW (1960) Time and space and variation of species. Ecology 41:611-627

Smith DG (2001) Pennak's freshwater invertebrates of the United States: Porifera to Crustacea, 4th edn. Wiley, New York

Stewart RE, Kantrud HA (1971) Classification of natural ponds and lakes in the glaciated prairie region. Bureau of Sport Fisheries and Wildlife, Resource Publication 92

Stewart RE, Kantrud HA (1972) Vegetation of prairie potholes, North Dakota, in relation to quality of water and other environmental factors. U.S. Geological Survey Professional Paper 585-D

Swanson GA (1978) Funnel trap for collecting littoral aquatic invertebrates. Prog Fish Cult 40:73

Thorp JH, Covich AP (1991) Ecology and classification of North American freshwater invertebrates. Academic, New York

Tomasovych A, Kidwell SM (2010) Predicting the effects of increasing temporal scale on species composition, diversity, and rank-abundance distributions. Paleobiology 36:672-695

Vihervaara P, D'Amato D, Forsius M, Angelstam P, Baessler C, Balvanera P, Boldgiv B, Bourgeron P, Dick J, Kanka R, Klotz S, Maass M, Melecis V, Petř́k P, Shibata H, Tang J, Thompson J, Zacharias S (2013) Using long-term ecosystem service and biodiversity data to study the impacts and adaptation options in response to climate change: insights from the global ILTER Sites Network. Curr Opin Environ Sustain 5:53-56

White EP, Adler PB, Lauenroth WK, Gill RA, Greenberg D, Kaufman DM, Rassweiler A, Rusak JA, Smith MD, Steinbeck JR, Waide RB, Yao J (2006) A comparison of the species-time relationship across ecosystems and taxonomic groups. Oikos 112:185-195 
Whittaker RH (1960) Vegetation of the Siskiyou Mountains, Oregon and California. Ecol Monogr 30:279-338

Winter TC (2003) Hydrological, chemical, and biological characteristics of a prairie pothole wetland complex under highly variable climate conditions-the Cottonwood Lake Study Area, east-central North Dakota. U.S. Geological Survey Professional Paper 1675

Winter TC, Rosenberry DO (1998) Hydrology of prairie pothole wetlands during drought and deluge: a 17-year study of the Cottonwood Lake wetland complex in North Dakota in the perspective of longer term measured and proxy hydrological records. Clim Change 40:189-209

Zajac RN, Vozarik JM, Gibbons BR (2013) Spatial and temporal patterns in macrofaunal diversity components relative to sea floor landscape structure. PLoS ONE 8:e65823

Publisher's Note Springer Nature remains neutral with regard to jurisdictional claims in published maps and institutional affiliations. 